\title{
Simulated Rainfall and Mowing Impact Fungicide Performance When Targeting Dollar Spot in Creeping Bentgrass
}

\author{
R. L. Pigati, P. H. Dernoeden, and A. P. Grybauskas, Department of Plant Science and Landscape Architecture, \\ University of Maryland, College Park 20742; and B. Momen, Department of Environmental Science and Technol- \\ ogy, University of Maryland, College Park 20742
}

\begin{abstract}
Pigati, R. L., Dernoeden, P. H., Grybauskas, A. P., and Momen, B. 2010. Simulated rainfall and mowing impact fungicide performance when targeting dollar spot in creeping bentgrass. Plant Dis. 94:596-603.

In this 2-year field study, four chemically diverse fungicides (i.e., chlorothalonil, boscalid, iprodione, and propiconazole) were evaluated for their ability to control dollar spot (Sclerotinia homoeocarpa) in creeping bentgrass (Agrostis stolonifera) as affected by simulated rain and mowing timing. Simulated rain ( 25 to $32 \mathrm{~mm}$ ) was imposed about 30 min after fungicide application and was compared to rain-free plots. One set of plots was mowed in the morning when the canopy was wet with dew and compared to plots that were mowed when the canopy was dry in the afternoon. The percent reduction in dollar spot control associated with simulated-rain versus rain-free treatments in 2007 and 2008, respectively, was as follows: chlorothalonil 67 and 83\%; propiconazole 42 and 79\%; boscalid 48 and 70\%; and iprodione 33 and 66\%. When disease pressure was low, all fungicides subjected to simulated rain provided effective dollar spot control for 7 or more days following the initial application in each year. Across all fungicidetreated plots over 2 years, the average percent reduction in dollar spot associated with morning mowing ranged from 54 to $65 \%$. The reduction in dollar spot severity in morning-mowed plots improved the performance of all fungicides.
\end{abstract}

Numerous biological agents and cultural practices have shown some success in suppressing dollar spot (Sclerotinia homoeocarpa F.T. Bennett) of turfgrasses. However, fungicides remain necessary to maintain acceptable levels of turf quality at many golf courses. Fungicides targeting dollar spot need to be applied on 7- to 28day intervals to maintain effective disease control (17). The timing of fungicide applications on golf courses can be complicated by special events, heavy play, and weather. Applications are sometimes performed when rain is in the forecast or when unpredicted storm activity develops. Furthermore, golf course fairways are mowed several times weekly, and clippings often are removed. The effects of mowing just prior to and after the application of fungicides has not been investigated.

Most research to evaluate the effect of rainfall following fungicide application has been conducted on crops other than turf. Chlorothalonil has been the most commonly evaluated fungicide for rainfastness. Several studies have shown that increasing the intensity of rainfall in-

Corresponding author: P. H. Dernoeden

E-mail: pd@umd.edu

Accepted for publication 26 January 2010.

doi:10.1094/PDIS-94-5-0596

(C) 2010 The American Phytopathological Society creased the amount of chlorothalonil displaced from plant foliage $(3,10,12,15)$. In a study involving the dynamics of chlorothalonil residues on potato (Solanum tuberosum L.) foliage, rainfall affected displacement of chlorothalonil more than any other weather factor (3). The aforementioned study showed that the resistance to chlorothalonil displacement from potato leaves increased as time between its application and simulated rainfall was increased. Fife and Nokes (12) evaluated the effect of rainfall duration and intensity on the persistence of chlorothalonil on tomato (Lycopersicon esculentum Mill.) foliage. They concluded that most of the chlorothalonil was displaced with a small amount of rain, but the chlorothalonil that was not initially washed off was very difficult to remove by rain. The authors hypothesized that the chlorothalonil remaining after initial displacement was held within the leaf matrix and thus was not easily removed by rainfall, regardless of intensity or duration.

We are aware of only two fungicide wash-off studies conducted in turf, and both involved chlorothalonil $(5,6)$. Carroll et al. (5) reported that increased rainfall intensities (18.6 versus $39.9 \mathrm{~mm}$ per h) increased the amount of chlorothalonil that was displaced from plant surfaces. Carroll et al. (6) measured the residence time (i.e., the time between chemical application and being subjected to wash-off) of three formulations of chlorothalonil on fairway height creeping bentgrass (Agrostis stolonifera $\mathrm{L}$.) foliage after a simulated-rainfall event. Flowable, water dispersible granule and granular chlorothalonil formulations were evaluated, but they did not detect any wash-off differences among formulations for any residence time. However, there were differences in the level of chlorothalonil displaced depending on length of rain-free period after fungicide application. They found that $35 \%$ of chlorothalonil was displaced from creeping bentgrass foliage when turf was subjected to a rainfall event $1 \mathrm{~h}$ after the fungicide was applied. Simulated rain imposed 8,24 , and $72 \mathrm{~h}$ after application resulted in 10 to $15 \%$ of the chlorothalonil being displaced.

Couch (7) conducted a postapplication irrigation study on putting green height creeping bentgrass that was $60 \%$ blighted by $S$. homoeocarpa at the time of fungicide application. The fungicides were applied twice on a 7-day interval, and the study was not repeated. He found that the effectiveness of contact fungicides (i.e., anilizine, chlorothalonil, and cycloheximide) was completely lost when they were subjected to irrigation prior to drying on the leaves. The performance of two penetrants (i.e., fenarimol and triadimefon) varied and ranged from 50 to $100 \%$ effectiveness when subjected to irrigation before drying. All fungicides evaluated, however, provided effective dollar spot control when treated sites were irrigated soon after the chemical had dried on the leaves (7).

The presence of canopy dew is known to increase disease severity in turfgrasses. Disease generally is promoted when leaf wetness duration is prolonged and by nutrients present in guttation fluids. Such nutrients, including amino acids, sugars, and other carbohydrates, can enhance pathogen growth and their ability to penetrate tissue $(8,13,18)$. Dew on the plant surface also assists the pathogen in adhering itself to the plant surface, which further helps the pathogen to resist displacement by flowing water (1). Furthermore, the presence of dew aids in hyphal growth by providing a source of free water and by maintaining fungal turgidity (14). The displacement of dew by mowing or poling in the morning has been shown to decrease the severity of dollar spot $(11,24)$.

To our knowledge, the effects of simulated or natural rainfall and mowing timing on the performance of fungicides used to 
target a turfgrass disease have not been studied. Therefore, our objectives in this field study were: (i) to determine the effect of a simulated-rain event applied approximately 30 min after the application of four chemically diverse fungicides on fungicide efficacy against dollar spot; and (ii) to determine if morning mowing to displace dew prior to fungicide application would affect fungicide performance compared to mowing a dry canopy in the afternoon.

\section{MATERIALS AND METHODS}

This study was conducted in the field at the University of Maryland Paint Branch Turfgrass Research Facility in College Park, MD. Soil was a Keyport silt loam (fine, mixed, semiactive, mesic Aquic Hapludult) with a $\mathrm{pH}$ of 6.0 and $16 \mathrm{~g}$ of organic matter per $\mathrm{kg}$ soil. A 50:50 vol/vol blend of 'Crenshaw' and 'Backspin' creeping bentgrass was established in September 2006 in eight independently irrigated main plots. Both Backspin and Crenshaw are very susceptible to dollar spot. There was a $7.6-\mathrm{m}$ perennial ryegrass (Lolium perenne L.) buffer around each main plot. The creeping bentgrass received 150 and $100 \mathrm{~kg} \mathrm{~N} / \mathrm{ha}$ in the autumn of 2005 and 2006, respectively, and $100 \mathrm{~kg} \mathrm{~N} / \mathrm{ha}$ in the spring of 2006 and 2007. No fertilizer was applied to the site during the study period.

The treatment structure was a $2 \times 2 \times 5$ factorial consisting of two simulated-rain levels (simulated rain or rain-free), two mowing times (morning or afternoon), and four fungicides and an untreated control. Treatments, which are described below, were assigned to field plots as a strip-splitplot design in which the two simulatedrain levels were first assigned randomly to eight $(3.1 \times 12.2 \mathrm{~m})$ main plots (i.e., four replications of the main plots). Then, the two mowing levels were randomly assigned to strips $(1.5 \times 7.5 \mathrm{~m})$ within the main plots. Finally, the four fungicides were assigned randomly to strips $(1.5 \times 3.0$ $\mathrm{m})$ within the main plots, which were perpendicular to the mowing level strips. This design required identification of two separate error terms for the main and strip-plot effects within the data analyses, which were performed using the SAS MIXED procedure.

Each main plot was outfitted with popup, matched precipitation spray irrigation heads (Weathermatic Model 5520; Weathermatic Irrigation Company, Dallas, TX). Since it has been shown that a turfgrass irrigation system can be employed to effectively simulate rainfall (2), the term simulated rain will be used to describe these treatments. Prior to initiating the study in 2007 and 2008, the irrigation system was calibrated by placing 18 cans in each main plot and irrigation heads were adjusted as needed to ensure uniform water delivery. The amount of water delivered to each main plot ranged from 25 to $32 \mathrm{~mm}$ after $8 \mathrm{~min}$. In a 2006 pilot study, few dif- ferences in dollar spot control were detected among the same fungicides and rates assessed in the current study using about $6.5 \mathrm{~mm}$ of simulated rain $60 \mathrm{~min}$ after fungicide application. Therefore, in the current study the amount of simulated rain was increased, and time between fungicide application and simulated rain was reduced. Hence, four main plots received approximately 25 to $32 \mathrm{~mm}$ of water in an 8-min period within 30 to $40 \mathrm{~min}$ of fungicide application, as described below. Otherwise, plots were not irrigated for several days or until there were visual signs of wilting.

In 2007 and 2008, the following fungicides and rates were assessed: chlorothalonil (tetrachloroisophthalonitrile; Daconil Ultrex 87.5 DG; Syngenta Crop Protection, Inc., Greensboro, NC) applied at 8.1 $\mathrm{kg}$ a.i./ha; propiconazole [1- $\left(2-\left(2^{\prime}, 4^{\prime}-\mathrm{di}-\right.\right.$ chlorophenyl)-4-propyl-1,3-dioxolan-2-ylmethyl)-1H-1,2,4-triazole; Banner MAXX 1.3 ME; Syngenta] applied at $0.5 \mathrm{~kg}$ a.i./ha; iprodione [3-(3,5-dichlorophenyl)$\mathrm{N}$-(1-methylethyl)-2, 4-dioxo-1-imidazolidinecarboxamide; Chipco 26GT 2SC; Bayer Environmental Sciences, Research Triangle Park, NC] applied at $3.1 \mathrm{~kg}$ a.i./ha; and boscalid [3-pyridinecarboxamide, 2-chloro- $N$-(4'-chloro(1, $1^{\prime}$-biphenyl)-2-yl); Emerald 70WG; BASF Corporation, Research Triangle Park, NC] applied at $0.28 \mathrm{~kg}$ a.i./ha. To minimize the potential influence of fungicide effects and inoculum levels from the previous year, the simulated-rain main plots were reversed in the second year and fungicide treatments were re-randomized. In both years, the main plots for the simulated-rain and rainfree levels each contained four fungicide treatments and one untreated control. The main plots were divided in half and mowed in a strip for the assignment of mowing in either the morning or afternoon. The strip was mowed in each main plot using a Jacobson Greens King IV (Textron Inc., Providence, RI) triplex mower, and clippings were removed prior to each fungicide application at about $0700 \mathrm{~h}$ when the canopy was wet with dew. These morning strips always were mowed in the morning throughout the study. The afternoon strips were mowed the day following each fungicide application after the canopy was dry (i.e., typically between 1200 and $1400 \mathrm{~h}$ ) and clippings were collected. On days when no fungicide applications were made, plots were mowed three times a week to a height of about $12 \mathrm{~mm}$, and clippings were removed. All fungicides were applied in 468 liters of water per hectare using a $\mathrm{CO}_{2}$ pressurized backpack sprayer $(262 \mathrm{kPa})$ equipped with one 8004E Tee Jet flat fan nozzle (Spraying Systems, Wheaton, IL).

The initial application of fungicide treatments was made between 0730 and $0800 \mathrm{~h}$ by two people and completed in about 9 to $10 \mathrm{~min}$. Subsequent applications were performed by one person in about 5 min. All fungicides were applied initially on 3 July 2007 and 7 August 2008, when dollar spot was active but disease pressure was low, averaging $\leq 5 \mathrm{~S}$. homoeocarpa infection centers (IC) per plot. It required less than 10 min to apply all treatments so that simulated rain was imposed about 30 to 40 min after the last and first treatments were applied, respectively. Since the canopy remained moist in morning-mowed plots by the time the last treatment was applied, it is not likely that any chemical had fully dried on foliage prior to being subjected to simulated rain. The canopy was wet with dew at the time fungicides were applied to afternoon-mowed plots.

The site was not inoculated and dollar spot developed naturally. Dollar spot was assessed by counting the number of $S$. homoeocarpa IC per plot about three times weekly. A reapplication threshold of 20 IC was chosen to ensure that creeping bentgrass did not sustain severe damage and that more rapid recovery would occur after fungicide reapplication. In 2007, a fungicide was reapplied when the average number of IC exceeded 20 in two of four replicates of a fungicide within a simulated-rain or rain-free treatment. When the threshold was reached, which occurred first in simulated-rain plots, all simulated-rain and rain-free plots within that particular fungicide treatment were retreated. In 2008, a fungicide was not reapplied until all four replicates of that fungicide within a rain treatment had exceeded the 20 IC threshold. The threshold was changed in 2008 in an attempt to obtain greater separation among simulated-rain and mowing treatments. It should be noted that the thresholds were not intended to mimic accepted levels of dollar spot for golf courses. Most golf course superintendents would establish an action threshold at $<10$ IC per 4.5 $\mathrm{m}^{2}$ for fairways. Thresholds, however, were used in this study as a guideline for the reapplication of fungicides and as a point of reference for the discussion of results. The reapplication dates in 2007 for each fungicide were as follows: chlorothalonil on 26 July and 10 August; and boscalid, iprodione, and propiconazole on 31 July. In 2008, chlorothalonil was reapplied on 5 and 11 September; iprodione was reapplied on 13 September; and propiconazole and was reapplied on 16 September. Boscalid was applied only once in 2008.

Generally there are two dollar spot epidemics in cool-season climates, one in early summer and one in late summer $(21,23)$. It is not unusual for dollar spot symptoms to subside following the earlysummer epidemics in May and June in Maryland, and turf can recover partially or fully prior to the second late-summer epidemic. Sustained and severe dollar spot epidemics, however, are common in midto-late summer in Maryland $(9,19)$. To avoid fluctuations in dollar spot activity, 
the study area was kept dollar spot free during early-summer epidemics in both years. Hence, treatments were not imposed until 3 July 2007 and 7 August 2008, when sustained and severe dollar spot pressure were most likely. To maintain healthy turf during early summer, the entire study site was treated on 1 June 2007 with chlorothalonil (7.6 kg a.i./ha). Early-season dollar spot was controlled in 2008 by applying chlorothalonil ( $8.1 \mathrm{~kg}$ a.i./ha) plus boscalid (0.39 kg a.i./ha) on 23 May and chlorothalonil (5.1 kg a.i./ha) plus propiconazole (0.5 kg a.i./ha) on 20 June.

Area under the disease progress curve (AUDPC) data were calculated by the trapezoidal method (4). All data were as- sessed for violation of the assumptions of the analysis of variance (ANOVA) using the SAS Plot procedure (SAS version 9.1, SAS Institute, Cary, NC), and transformed when necessary. Preplanned orthogonal contrasts were used to examine the effects of simulated rain versus rain-free and morning versus afternoon mowing treatments on fungicide performance. To obtain contrasts, data were combined over the two mowing timing treatments for simulated rain and combined over the two rain treatments to obtain mowing timing contrasts. Untreated control data were not utilized in the preplanned comparisons. Data collected on individual rating dates were square root transformed for analysis in the preplanned contrasts, but actual means are shown. The AUDPC data were normally distributed, and thus were not transformed. Percentages shown in the text were calculated as follows: $\left(\mathrm{AUDPC}_{\text {simulated rain or } \mathrm{PM}}-\right.$ $\left.\mathrm{AUDPC}_{\text {rain-free or AM}}\right) / \mathrm{AUDPC}_{\text {simulated rain or PM}}$.

\section{RESULTS}

Simulated rain. Dollar spot developed faster and was more severe in 2007 than in 2008. When averaged over fungicide treatments, there was more dollar spot in simulated-rain versus rain-free plots in 2007 and 2008 as measured by AUDPC (Table 1). On individual rating dates, there was one date in 2007 and 11 dates in 2008, when there was a significant rain $\times$ chemical interac-

Table 1. Area under the disease progress curve (AUDPC) and probability of significance ( $P$ level) for the effect of simulated-rain versus rain-free treatment on the efficacy of four fungicides targeting Sclerotinia homoeocarpa in creeping bentgrass in 2007 and 2008

\begin{tabular}{|c|c|c|c|c|c|c|}
\hline \multirow[b]{3}{*}{ Fungicide } & \multicolumn{6}{|c|}{ AUDPC } \\
\hline & \multicolumn{3}{|c|}{2007} & \multicolumn{3}{|c|}{2008} \\
\hline & Simulated $\operatorname{rain}^{y}$ & Rain free ${ }^{z}$ & $P$ level & Simulated rain & Rain free & $P$ level \\
\hline Chlorothalonil & 726 & 237 & 0.002 & 1,123 & 196 & 0.002 \\
\hline Propiconazole & 658 & 382 & 0.059 & 528 & 112 & 0.057 \\
\hline Boscalid & 364 & 191 & 0.225 & 321 & 96 & 0.255 \\
\hline Iprodione & 428 & 288 & 0.324 & 363 & 123 & 0.228 \\
\hline Average & 544 & 274 & 0.037 & 536 & 153 & 0.081 \\
\hline
\end{tabular}

y Plots were subjected to simulated rain $(25$ to $32 \mathrm{~mm}$ ) within about $30 \mathrm{~min}$ following fungicide application.

${ }^{\mathrm{z}}$ Plots were not subjected to simulated rain or irrigated within $24 \mathrm{~h}$ of fungicide application.
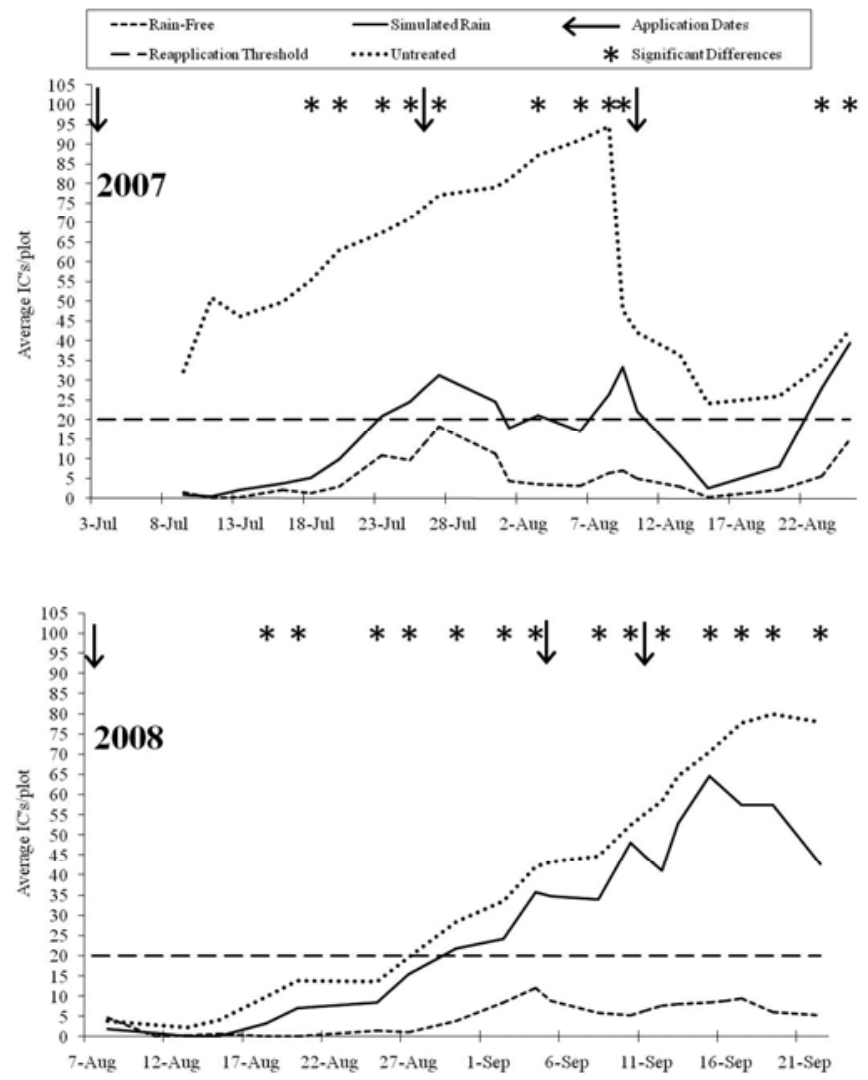

Fig. 1. Sclerotinia homoeocarpa infection centers (IC) in plots treated with chlorothalonil and subjected to simulated-rain versus rain-free treatments in 2007 and 2008. Preplanned orthogonal contrasts between values for simulated-rain and rain-free treatments on dates marked by an asterisk $(*)$ were significantly different at $P \leq 0.05$. Untreated control data were not included in the analyses.
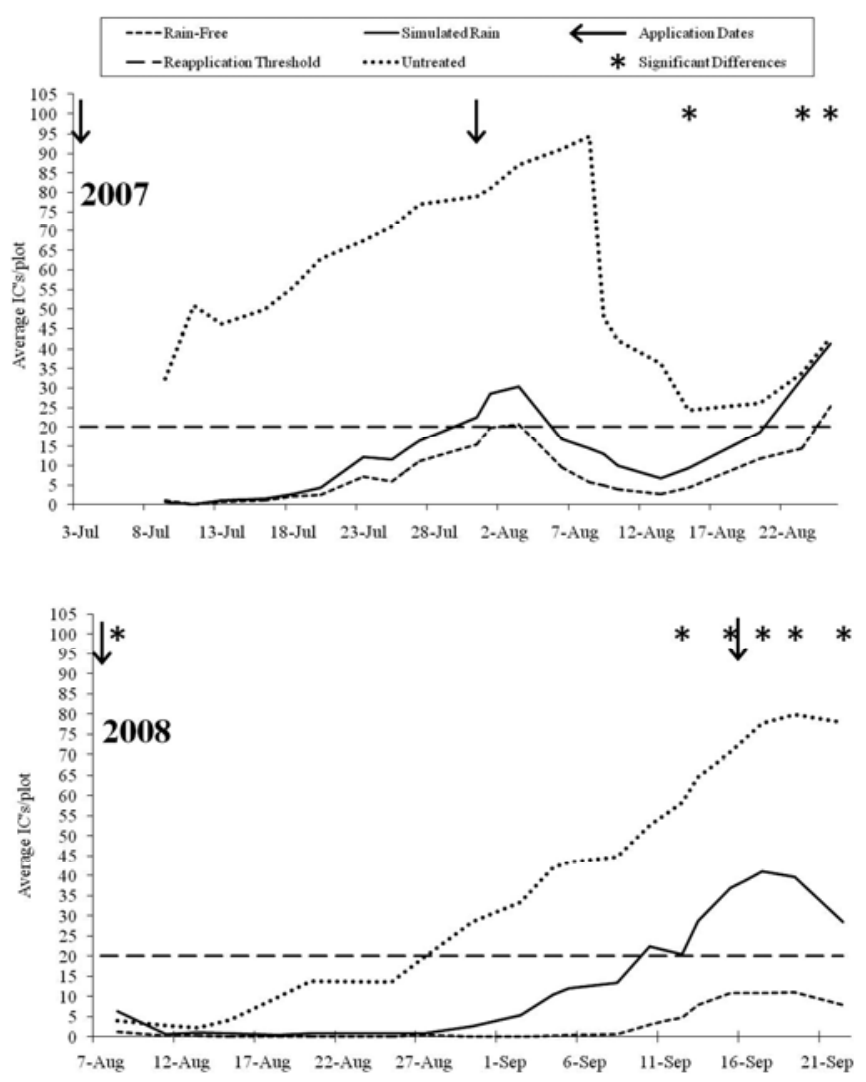

Fig. 2. Sclerotinia homoeocarpa infection centers (IC) in plots treated with propiconazole and subjected to simulated-rain versus rain-free treatments in 2007 and 2008. Preplanned orthogonal contrasts between values for simulated-rain and rain-free treatments on dates marked by an asterisk $(*)$ were significantly different at $P \leq 0.05$. Untreated control data were not included in the analyses. 
tion, thus only preplanned contrasts will be discussed. Dollar spot resurgence (i.e., a rapid increase in blighting) occurred in all fungicide-treated plots by late August in 2007, but none occurred in 2008.

There was a greater amount of dollar spot $(P=0.002)$ in chlorothalonil-treated plots subjected to simulated rain versus rain-free in both 2007 and 2008 (Table 1). Significantly more IC developed in chlorothalonil-treated plots subjected to simulated rain compared to rain-free plots on 11 of 18 rating dates in both years (Fig. 1). Chlorothalonil-treated plots subjected to simulated rain had dollar spot levels that exceeded the reapplication threshold three times during the season; whereas rain-free plots had dollar spot levels below the threshold on all dates in both years. Chlorothalonil-treated plots subjected to simulated rain first exceeded the threshold 20 days after the initial application on 23 July 2007. Blighting increased for $24 \mathrm{~h}$ before the number of IC dropped below the threshold and remained suppressed for about 6 days. The threshold was again exceeded on 3 August 2007 in simulatedrain plots only. Dollar spot levels fell sharply in simulated-rain plots following the third chlorothalonil application to very low levels by 15 August, but increased rapidly thereafter and exceeded the thresh- old on 23 August 2007. Once the threshold was exceeded in 2008, plots subjected to simulated rain after subsequent chlorothalonil applications had dollar spot levels that remained above the threshold.

There was more dollar spot in simulated-rain versus rain-free propiconazoletreated plots in $2007(P=0.059)$ and 2008 $(P=0.057)$ (Table 1$)$. Significantly more IC developed in simulated-rain versus rainfree propiconazole-treated plots on three assessment dates in 2007 and on five assessment dates in 2008 (Fig. 2). Propiconazole-treated plots subjected to simulated rain had dollar spot levels that exceeded the reapplication threshold twice in 2007 and once in 2008. Following the second propiconazole application in 2007 , blight ratings continued to increase for 3 days before declining below the threshold. On 23 and 25 August 2007, dollar spot levels exceeded the threshold in simulatedrain and rain-free plots, respectively. In 2008, dollar spot rose to the threshold on 10 September in the simulated-rain plots and remained above the threshold for the remainder of the study. Dollar spot levels in rain-free plots only exceeded the threshold at the end of the season in 2007; however, rain-free plots treated with propiconazole did not exceed the threshold on any date in 2008 .
Although a similar pattern of greater dollar spot levels in simulated-rain versus rain-free plots was observed for boscalid and iprodione, the AUDPC data were not significantly different for either fungicide in both years (Table 1). There were significantly $(P \leq 0.05)$ more IC in simulatedrain versus rain-free plots on several dates early in the season for boscalid (Fig. 3) and on a few late dates for iprodione (Fig. 4) in both years, but the differences were small. The reapplication threshold was exceeded on two to three dates in 2007 and 2008 for both fungicides in plots subjected to simulated rain. The threshold was not exceeded in rain-free plots treated with boscalid (2007 and 2008) or iprodione (2008). Rain-free plots treated with iprodione only exceeded the threshold in late August 2007, about 21 days since the fungicide was last applied.

Morning versus afternoon mowing. When data were averaged across both rain treatments, less dollar spot developed in morning- versus afternoon-mowed plots (Table 2). Chlorothalonil performance was impacted most by mowing $(P=0.003$ in 2007 and $P<0.001$ in 2008). Propiconazole and boscalid also performed better with morning mowing, especially in 2007 when disease pressure was greater $(P=$ 0.022 and $P=0.089$, respectively).
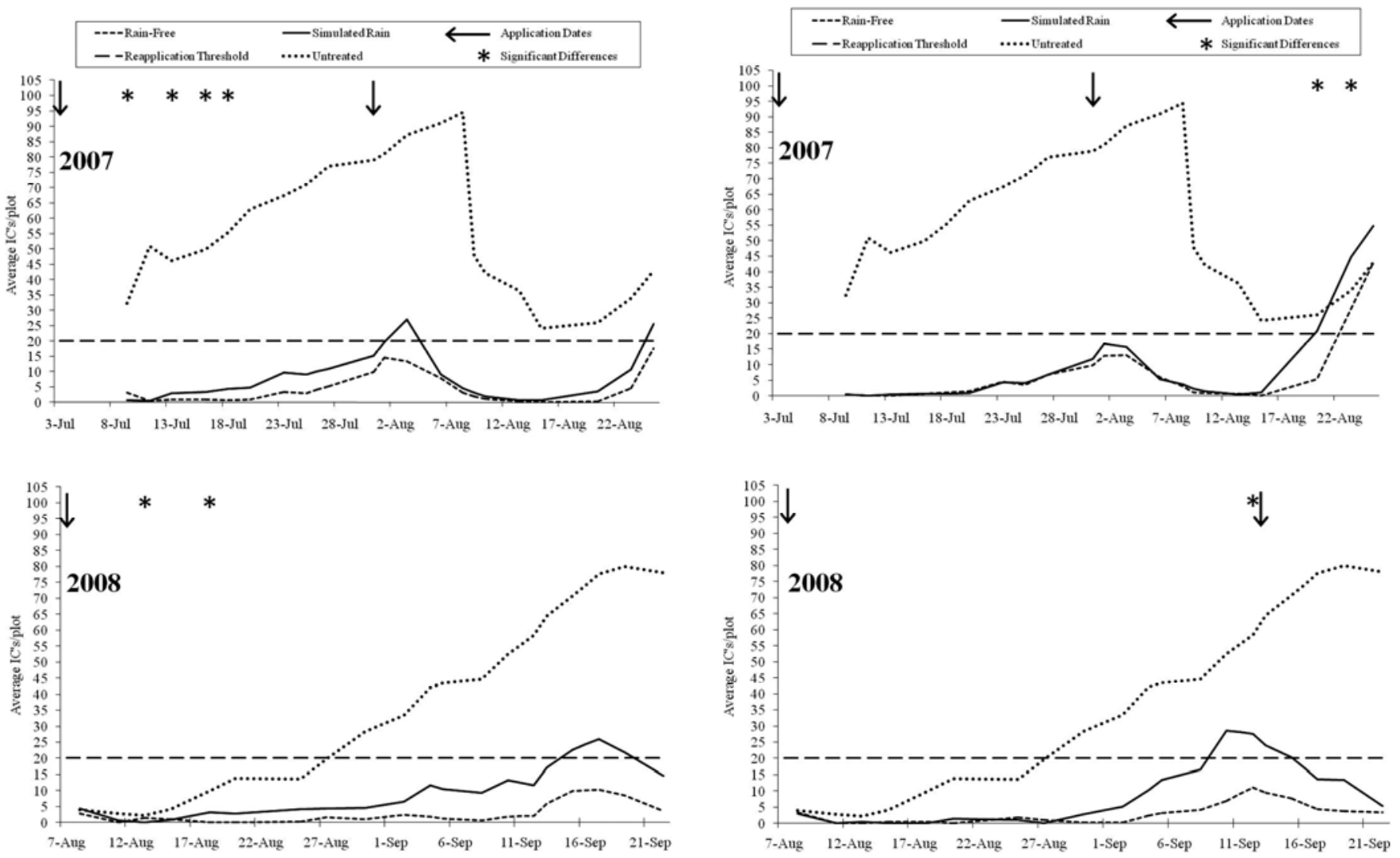

Fig. 3. Sclerotinia homoeocarpa infection centers (IC) in plots treated with boscalid and subjected to simulated-rain versus rain-free treatments in 2007 and 2008. Preplanned orthogonal contrasts between values for simulatedrain and rain-free treatments on dates marked by an asterisk $\left({ }^{*}\right)$ were significantly different at $P \leq 0.05$. Untreated control data were not included in the analyses.

Fig. 4. Sclerotinia homoeocarpa infection centers (IC) in plots treated with iprodione and subjected to simulated-rain versus rain-free treatments in 2007 and 2008. Preplanned orthogonal contrasts between values for simulated-rain and rain-free treatments on dates marked by an asterisk (*) were significantly different at $P \leq 0.05$. Untreated control data were not included in the analyses. 
Differences between mowing timings were first observed for chlorothaloniltreated plots on 18 July 2007 and on 20 August 2008. Dollar spot levels were greater in afternoon- versus morningmowed plots on most rating dates thereafter (Fig. 5). Dollar spot levels generally remained below the threshold on most dates in morning-mowed plots, but exceeded the threshold in afternoon-mowed plots three times in 2007 and once in 2008. There was a greater tendency to remain near or above the threshold in afternoonmowed plots once the threshold was exceeded.

Propiconazole also performed better in morning- versus afternoon-mowed plots in
2007 (Table 2). The only date prior to the second application when significantly fewer IC were observed in morning- versus afternoon-mowed plots was 20 July 2007 (Fig. 6). Following propiconazole reapplication in 2007, there were fewer IC in morning- versus afternoon-mowed plots on most rating dates. There were no differences due to mowing among individual rating dates in 2008 .

Dollar spot levels generally were lower in morning- versus afternoon-mowed plots treated with boscalid in $2007(P=0.089)$ and $2008(P=0.109)$ (Table 2 and Fig. 7). The numbers of IC were significantly higher in boscalid-treated plots subjected to afternoon versus morning mowing on 7 of 19 rating dates in 2007, and on 3 of 18 rating dates in 2008 .

There were no significant differences in AUDPC or disease severity on individual rating dates for the mowing timings in iprodione-treated plots in 2007 (Table 2 and Fig. 8). There was less dollar spot $(P=$ $0.101)$ in morning- than in afternoonmowed plots treated with iprodione in 2008. Dollar spot levels were greater in afternoon- versus morning-mowed plots on only 8, 10, and 12 September in 2008.

\section{DISCUSSION}

This study compared the level of dollar spot control among four fungicides as influenced by simulated rain and mowing

Table 2. Area under the disease progress curve (AUDPC) and probability of significance ( $P$ level) for the effect of mowing in the presence (morning) versus the absence (afternoon) of dew on the efficacy of four fungicides targeting Sclerotinia homoeocarpa in creeping bentgrass in 2007 and 2008

\begin{tabular}{|c|c|c|c|c|c|c|}
\hline \multirow[b]{3}{*}{ Fungicide } & \multicolumn{6}{|c|}{ AUDPC } \\
\hline & \multicolumn{3}{|c|}{2007} & \multicolumn{3}{|c|}{2008} \\
\hline & Morning ${ }^{y}$ & Afternoon $^{z}$ & $P$ level & Morning & Afternoon & $P$ level \\
\hline Chlorothalonil & 253 & 711 & 0.003 & 325 & 995 & $<0.001$ \\
\hline Propiconazole & 349 & 691 & 0.022 & 201 & 439 & 0.132 \\
\hline Boscalid & 154 & 401 & 0.089 & 81 & 336 & 0.109 \\
\hline Iprodione & 272 & 444 & 0.227 & 113 & 373 & 0.101 \\
\hline Average & 257 & 561 & 0.022 & 180 & 510 & 0.025 \\
\hline
\end{tabular}

y Plots were mowed in the morning prior to each fungicide application to remove dew; thereafter plots always were mowed in the morning in the presence of dew.

${ }^{\mathrm{z}}$ Plots were mowed in the afternoon $>24 \mathrm{~h}$ following each fungicide application; thereafter plots always were mowed in the afternoon when the canopy was dry.
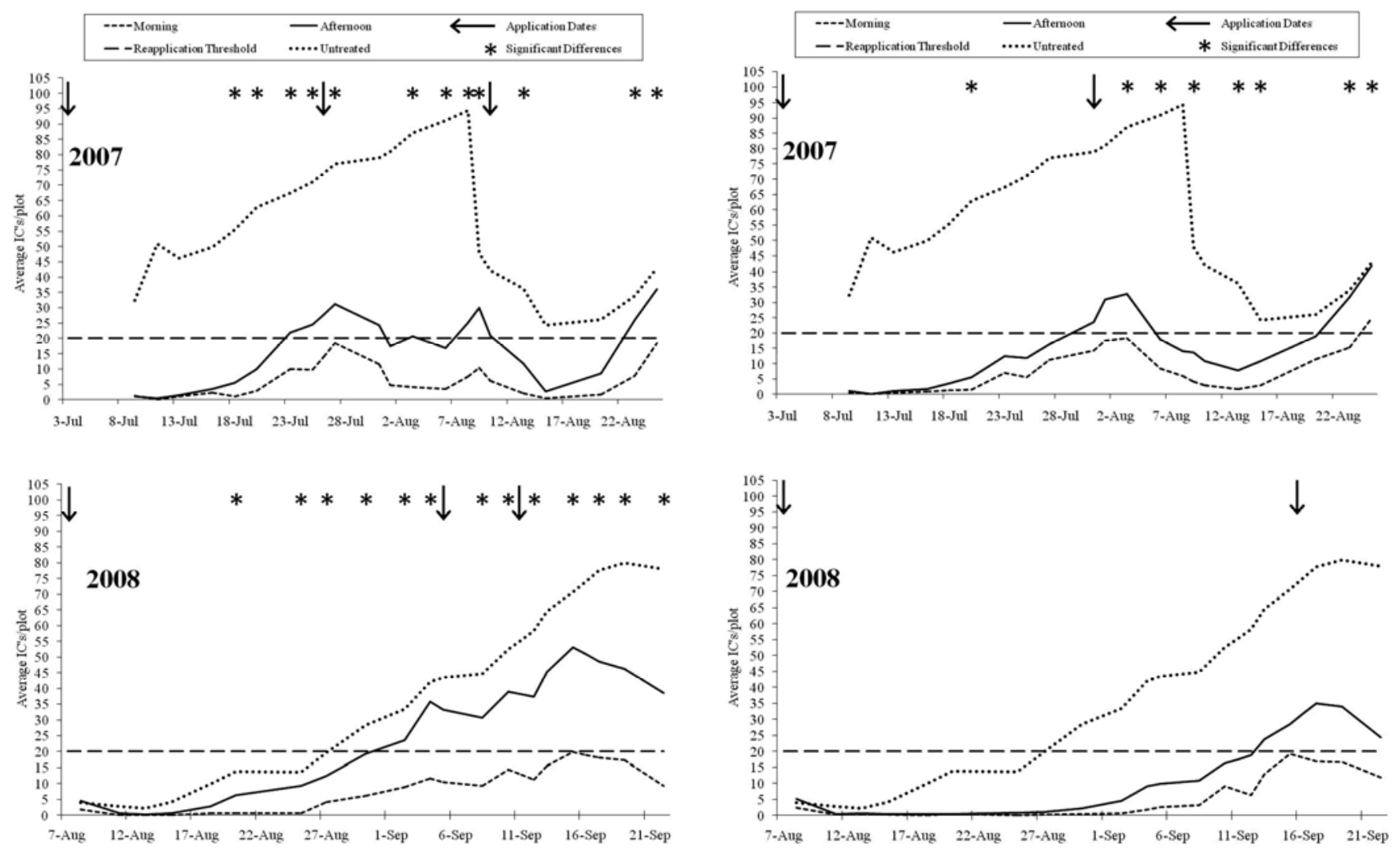

Fig. 5. Sclerotinia homoeocarpa infection centers (IC) in plots treated with chlorothalonil and subjected to morning versus afternoon mowing in 2007 and 2008. Preplanned orthogonal contrasts between values for morningand afternoon-mowed plots on dates marked by an asterisk $(*)$ were significantly different at $P \leq 0.05$. Untreated control data were not included in the analyses.

Fig. 6. Sclerotinia homoeocarpa infection centers (IC) in plots treated with propiconazole and subjected to morning versus afternoon mowing in 2007 and 2008. Preplanned orthogonal contrasts between values for morningand afternoon-mowed plots on dates marked by an asterisk $(*)$ were significantly different at $P \leq 0.05$. Untreated control data were not included in the analyses. 
timing. Plots subjected to simulated rain and afternoon mowing sustained more dollar spot injury than rain-free and morning-mowed plots in both 2007 and 2008. Chlorothalonil required more frequent application since its residual effectiveness was shorter-lived than the penetrants evaluated. Chlorothalonil is a contact protectant (i.e., active ingredient remains on plant surfaces); whereas the other fungicides are penetrants (i.e., some active ingredient is translocated into the plant). Penetrants are protected by virtue of some active ingredient being taken up into tissue; whereas the active ingredient of a contact fungicide is likely to be diminished more rapidly on plant surfaces by environmental forces.

A measure of the influence of rain may be to compare the percentage or number of days each fungicide provided a level of dollar spot control that was above or below the threshold in each year. A reapplication threshold was employed to determine potential differences among treatments, but was not intended to represent disease levels that would be considered acceptable by golf course superintendents. The percentage of days when $S$. homoeocarpa IC were below the threshold for each fungicide subjected to simulated-rain versus rain-free conditions was as follows: chlorothalonil
55 and $66 \%$ versus 100 and $100 \%$ of days; propiconazole 80 and $83 \%$ versus 98 and $100 \%$ of days; boscalid 89 and $100 \%$ versus 100 and $100 \%$ of days; and iprodione 82 and $94 \%$ versus 96 and $100 \%$ of days in 2007 and 2008, respectively. All fungicides applied to rain-free plots generally provided a level of dollar spot control that was below the threshold.

Another measure of the influence of simulated rain may be to examine the percent difference in IC between simulatedrain and rain-free treatments. The greater the percentage, the less rain-fast a fungicide would be. The ranges in the percentage of dollar spot reduction in simulatedrain versus rain-free plots for each fungicide treatment averaged over all rating dates in 2007 and 2008, respectively, were as follows: chlorothalonil 67 and 83\%; propiconazole 42 and $79 \%$; boscalid 48 and $70 \%$; and iprodione 33 and $66 \%$. Clearly, chlorothalonil was most negatively impacted by simulated rain. The larger AUDPC values and more numerous dates when propiconazole-treated plots subjected to simulated rain were above the threshold following the second application in each year compared to the other penetrants indicated that propiconazole provided an intermediate level of rainfastness. Boscalid and iprodione generally were the most rain-fast fungicides evaluated. It should be noted, however, that $S$. homoeocarpa isolates from the study site were shown to be less sensitive to propiconazole than baseline isolates in petri dish tests (G. Olaya, personal communication). Isolates from boscalid- and iprodionetreated plots were equal in sensitivity to base line isolates (M. Newnam, personal communication). Hence, the reduced sensitivity of the pathogen population to propiconazole in the study site may have influenced these results.

Most previous studies involving chlorothalonil and other contact fungicides generally demonstrated that a high intensity rainfall removed more fungicide from plant surfaces than a low intensity rainfall $(3,6,12,16)$. Average AUDPC data from the current study showed that simulated rain had reduced the ability of the fungicides to control dollar spot $(P \leq 0.081)$. In this study, plots were subjected to a simulatedrain event, which delivered water at a rate of approximately 19 to $24 \mathrm{~cm} / \mathrm{h}$ for $8 \mathrm{~min}$. A rainfall event of this intensity, having duration of $5 \mathrm{~min}$, has a return frequency of 50 to 100 years for nearby Silver Spring, MD (20). However, it is not unusual in Maryland for a rain event lasting several hours to deliver $25 \mathrm{~mm}$ or more water. Despite the high level of simulated
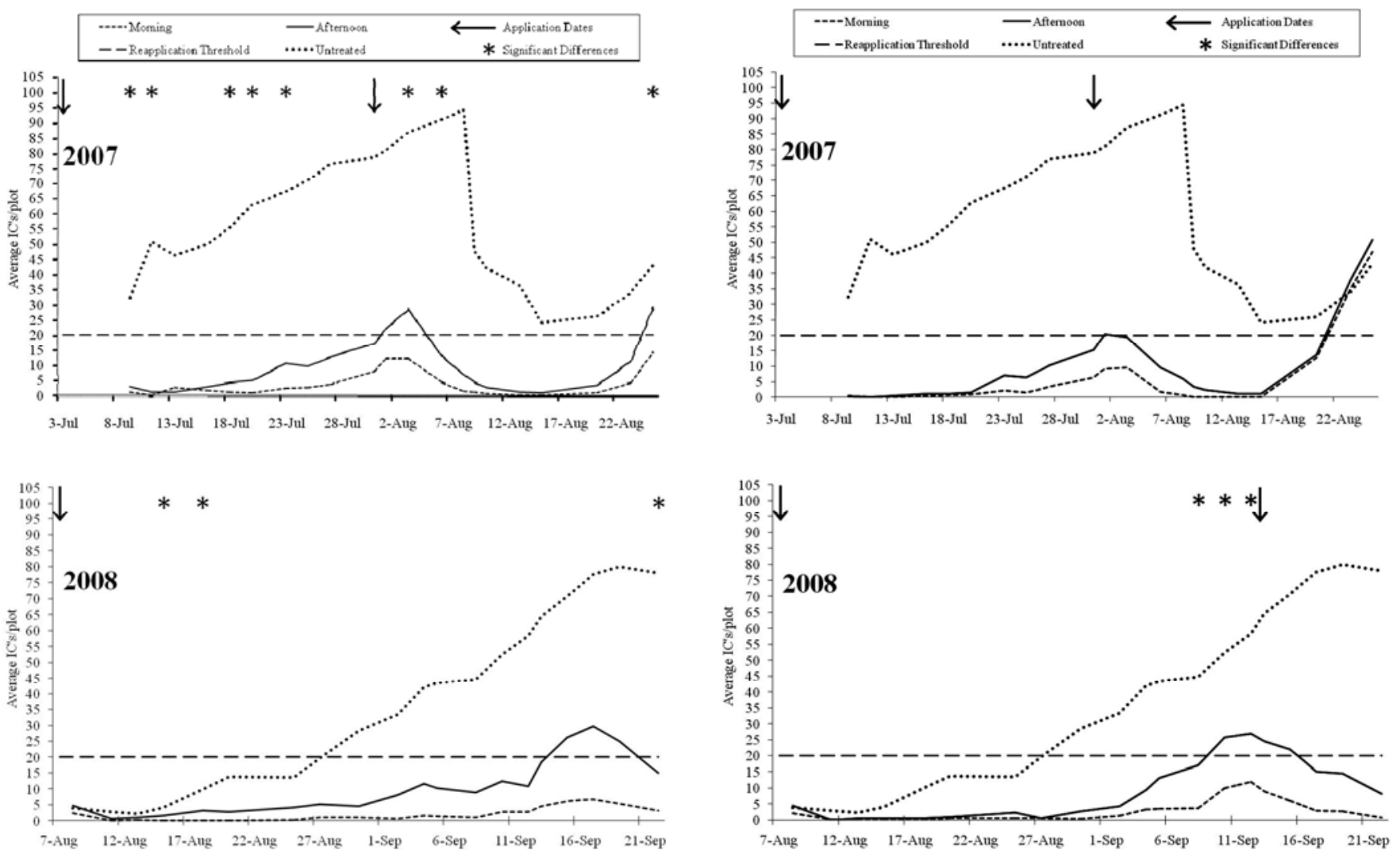

Fig. 7. Sclerotinia homoeocarpa infection centers (IC) in plots treated with boscalid and subjected to morning versus afternoon mowing in 2007 and 2008. Preplanned orthogonal contrasts between values for morning- and afternoon-mowed plots on dates marked by an asterisk (*) were significantly different at $P \leq 0.05$. Untreated control data were not included in the analyses.

Fig. 8. Sclerotinia homoeocarpa infection centers (IC) in plots treated with iprodione and subjected to morning versus afternoon mowing in 2007 and 2008. Preplanned orthogonal contrasts between values for morning- and afternoon-mowed plots on dates marked by an asterisk $(*)$ were significantly different at $P \leq 0.05$. Untreated control data were not included in the analyses. 
rain, chlorothalonil provided at least 7 days of effective dollar spot control following the initial application in both years when disease pressure was low but intensifying. Couch (7), however, observed that the effects of chlorothalonil and iprodione were rendered ineffective in controlling dollar spot by irrigating turf prior to the fungicide drying on foliage. Couch (7) also reported that fenarimol and triadimefon provided about 50 to $100 \%$ control when plots were irrigated before the chemicals had time to dry on surfaces. The three penetrants evaluated in this study provided a minimum of 10 days of effective control in simulated-rain plots following the initial application. About $35 \%$ of chlorothalonil can be displaced from creeping bentgrass foliage by rain within $1 \mathrm{~h}$ of application (6). Thus, it is likely that the generally poor performance of chlorothalonil, compared to rain-free plots, was due to its displacement from leaf surfaces by simulated rain. It is speculated that significant amounts of boscalid, iprodione, and propiconazole entered plant foliage directly or possibly from between sheaths within 30 min of application, but before the spray suspension could dry on the canopy. It also is possible that some of the fungicide that had washed off plants was taken up by roots. Since formulation can affect fungicide performance, these findings may only apply to the formulations evaluated (22).

Mowing in the morning versus afternoon had a large impact on decreasing disease pressure in both years. There were 54 and $65 \%$ fewer IC in plots subjected to morning versus afternoon mowing when data were averaged over all fungicides and rating dates in 2007 and 2008, respectively. Using AUDPC values, the average percentage of dollar spot reduction in morning- versus afternoon-mowed plots for each fungicide in 2007 and 2008, respectively, was as follows: chlorothalonil 64 and 67\%; propiconazole 50 and 54\%; boscalid 62 and $76 \%$; and iprodione 39 and $70 \%$. Untreated control data were not included in the statistical analyses for fungicide treatments; however, there was a $26 \%(P=0.088)$ and $23 \%(P=0.134)$ reduction in dollar spot (i.e., AUDPC) in morning- versus afternoon-mowed control plots in 2007 and 2008, respectively (data not shown). Except for iprodione in late August 2007, there were no dates in either year when plots subjected to morning mowing were above the threshold for any fungicide. Hence, the lower levels of dollar spot attributed to morning mowing improved the performance of all fungicides.

Williams et al. (24) reported that displacement of dew by mowing at $0700 \mathrm{~h}$ on fairway-height creeping bentgrass reduced the number of $S$. homoeocarpa infection centers 37 to $78 \%$ on selected rating dates, when compared to plots mowed at $1400 \mathrm{~h}$. Ellram et al. (11) found that plots that had dew displaced at $0400 \mathrm{~h}$ had about $40 \%$ less dollar spot when compared to plots subject to dew removal at $1000 \mathrm{~h}$ and about $15 \%$ less disease when dew was displaced at $2200 \mathrm{~h}$. Results of the current study confirm the beneficial effect of morning mowing on reducing dollar spot severity in fungicide-treated turf. Our observations indicated that another important factor in reducing dollar spot severity was the physical disruption of foliar $S$. homoeocarpa mycelium by mowing. Mowing in the morning not only reduced leaf wetness duration, but it physically disrupted and/or removed or otherwise displaced foliar mycelium. Furthermore, mycelium in infected tissue also would have been removed by collecting clippings. It should be noted, however, that Williams et al. (24) reported that returning versus collecting clippings when mowing had no consistent effect on dollar spot severity.

This research has shown that while simulated rain imposed within about 30 min of fungicide treatment diminished the level of dollar spot control over the long term, it did not render the treatment ineffective. This was especially true following the initial application of all fungicides in both years when disease pressure was low but increasing. Subsequent applications of chlorothalonil when disease pressure was higher generally were not effective in reducing dollar spot below the threshold when subjected to simulated rain. When subjected to simulated rain, boscalid, iprodione, and propiconazole provided effective control for 10 or more days following the initial application and were more effective in subsequent applications when disease pressure was higher compared to chlorothalonil. Hence, the results of this study have shown that if rain is forecast, and it is deemed necessary to apply a fungicide targeting dollar spot, then boscalid and iprodione would be the preferred products. Chlorothalonil use should be avoided if rain is likely, and propiconazole would be a better choice than chlorothalonil. Data showed that under low dollar spot pressure (i.e., <5 IC per $2.2 \mathrm{~m}^{2}$ plot), fungicides do not need to be reapplied immediately following a rain event occurring within about $30 \mathrm{~min}$ of treatment. However, under high dollar spot pressure (>20 IC per $2.2 \mathrm{~m}^{2}$ plot), rain within 30 min can diminish performance to below acceptable limits for golf course superintendents. Finally, this study showed that morning mowing can greatly reduce dollar spot severity and thus improve fungicide performance.

\section{ACKNOWLEDGMENTS}

We thank Michael Agnew, Ph.D., Syngenta Crop Protection, Inc.; Eastern Shore Association of Golf Course Superintendents; Mid-Atlantic Association of Golf Course Superintendents; and the United States Golf Association for their interest in and financial support of this project. We are grateful to Michael Newnam, Bayer Environmental Services, and Gilberto Olaya, Ph.D., Syngenta Crop Protection for testing isolates of Sclerotinia homoeocarpa from the study site for sensitivity to the fungicides evaluated. This research project was a contribution of the Maryland Agricultural Experiment Station.

\section{LITERATURE CITED}

1. Agrios, G. N. 2005. Plant Pathology. 5th ed. Elsevier Academic Press, San Diego, CA.

2. Bell, C., and Koh, K. 2008. A comparison of rainfall simulation and turfgrass irrigation for their effects on nutrient runoff from bermudagrass. Agron. Abstr. C-05-649-9.

3. Bruhn, J. A., and Fry, W. E. 1982. A mathematical model of the spatial and temporal dynamics of chlorothalonil residues on potato foliage. Phytopathology 72:1306-1312.

4. Campbell, C. L., and Madden, L. V. 1990 Introduction to Plant Disease Epidemiology. John Wiley \& Sons, New York.

5. Carroll, M. J., Hill, R. L., Pfeil, E., and Herner A. E. 1993. Washoff of chlorothalonil from turfgrass foliage. Int. Turfgrass Soc. Res. J. 7:964-970.

6. Carroll, M. J., Hill, R. L., Pfeil, E., and Krouse, J. M. 2001. Effect of residence time on washoff of chlorothalonil from turf foliage. Int. Turfgrass Soc. Res. J. 9:1-5.

7. Couch, H. B. 1985. Effect of post-spray rainfall or irrigation on the effectiveness of fungicides. Golf Course Manag. 53:50-58

8. Curtis, L. C. 1944. The exudation of glutamine from lawn grasses. Plant Physiol. 19:1-5.

9. Dernoeden, P. H., and Kaminski, J. E. 2000 Preventive dollar spot control with fungicides. Fungic. Nematicide Tests, 56:T9. DOI 10.10941/FN56. American Phytopathological Society, St. Paul, MN.

10. Elliott, V. J., and Spurr, H. W., Jr. 1993. Temporal dynamics of chlorothalonil residues on peanut foliage and the influence of weather factors and plant growth. Plant Dis. 77:455460.

11. Ellram, A., Horgan, B., and Hulke, B. 2007. Mowing strategies and dew removal to minimize dollar spot on creeping bentgrass. Crop Sci. 47:2129-2136.

12. Fife, J. P., and Nokes, S. E. 2002. Evaluation of the effect of rainfall intensity and duration on the persistence of chlorothalonil on processing tomato foliage. Crop Prot. 21:733740 .

13. Goatley, J. L., and Lewis, R. W. 1966. Composition of guttation fluid from rye, wheat, and barley seedlings. Plant Physiol. 41:373-375.

14. Jackson, N., and Howard, F. L. 1966. Fungi as agents of turfgrass disease. J. Sports Turf Res. Inst. 42:9-16.

15. Ko, W. H., Lin, H., and Kunimoto, R. K. 1975. A simple method for determining efficacy and weatherability of fungicides on foliage. Phytopathology 65:1023-1025.

16. Kudsk, P., and Mathiassen, S. K. 1991. Influence of formulation and adjuvants on the rainfastness of maneb and mancozeb on pea and potato. Pestic. Sci. 33:57-71.

17. Latin, R. 2006. Residual efficacy of fungicides for control of dollar spot on creeping bentgrass. Plant Dis. 90:571-575.

18. Marion, D. F. 1974. Leaf surface fluid composition of velvet bentgrass as affected by nitrogen fertility and its relationship to inoculum viability of Gloeocercospora sorghi and severity of copper spot disease. Ph.D. diss. University of Rhode Island, Kingston. (Diss. Abstr. $7517,865)$

19. McDonald, S. J., Dernoeden, P. H., and Bigelow, C. A. 2006. Dollar spot and gray leaf spo severity as influenced by irrigation, chlorothalonil, paclobutrazol, and a wetting agent. Crop Sci. 46:2675-2684

20. NOAA's National Weather Service. 2009 Precipitation Frequency Data Service (PFDS) 
http://hdsc.nws.noaa.gov. Accessed January 2010.

21. Powell, J. F., and Vargas, J. M., Jr. 2001. Vegetative compatibility and seasonal variation among isolates of Sclerotinia homoeocarpa. Plant Dis. 85:377-381.
22. Shepard, D., Agnew, M., Fidanza, M., Kaminski, J., and Dant, L. 2006. Selecting nozzles for fungicide spray applications. Golf Course Manag. 74:83-88.

23. Smith, J. D., Jackson, N., and Woolhouse, A. R. 1989. Fungal Diseases of Amenity Turf
Grasses. E. \& F.N. Spon, London.

24. Williams, D. W., Powell, A. J., Jr., Vincelli, P., and Dougherty, C. T. 1996. Dollar spot on bentgrass influenced by displacement of leaf surface moisture, nitrogen, and clipping removal. Crop Sci. 36:1304-1309. 